\title{
Maternal Intake of Methyl-Donor Nutrients and Child Cognition at 3 Years of Age
}

\author{
Eduardo Villamor ${ }^{\mathrm{a}, \mathrm{b}}$, Sheryl L. Rifas-Shiman ${ }^{\mathrm{c}}$, Matthew W. Gillman ${ }^{\mathrm{b}, \mathrm{c}}$ and Emily Oken \\ ${ }^{a}$ Department of Epidemiology, University of Michigan School of Public Health, Ann Arbor, MI, ${ }^{b}$ Department of Nutrition, Harvard School of \\ Public Health, and ' Obesity Prevention Program, Department of Population Medicine, Harvard Medical School/Harvard Pilgrim Health Care \\ Institute, Boston, MA, USA
}

Correspondence:

E. Villamor, Department of Epidemiology, University of Michigan School of Public Health, 1420 Washington Heights, SPH II, Ann Arbor, MI 48109, USA.

E-mail: villamor@umich.edu

\section{Summary}

Villamor E, Rifas-Shiman SL, Gillman MW, Oken E. Maternal intake of methyl-donor nutrients and child cognition at 3 years of age. Paediatric and Perinatal Epidemiology 2012; 26: 328-335.

Methyl-donor nutrients are substrates for methylation reactions involved in neurodevelopment processes. The role of maternal intake of these nutrients on cognitive performance of the offspring is poorly understood. We examined the associations of maternal intake of folate, vitamin B12, choline, betaine and methionine during the first and second trimesters of pregnancy, with tests of cognitive performance in the offspring at 3 years of age using data from 1210 participants in Project Viva, a prospective pre-birth cohort study in Massachusetts. We assessed nutrient intake with the use of food frequency questionnaires. Children's cognition at age 3 years was evaluated with the Peabody Picture Vocabulary Test III (PPVT-III) and visual-motor skills with the Wide Range Assessment of Visual Motor Abilities test. In multivariable models adjusting for potential sociobehavioural and nutritional confounders, for each $600 \mu \mathrm{g} / \mathrm{day}$ increment in total folate intake during the first trimester, PPVT-III score at age 3 years was 1.6 points [ $95 \%$ confidence interval $(\mathrm{CI}) 0.1,3.1 ; P=0.04$ ] higher. There was a weak inverse association between vitamin B12 intake during the second trimester and PPVTIII scores [ -0.4 points per $2.6 \mu \mathrm{g} /$ day; $95 \% \mathrm{CI}-0.8,-0.1 ; P=0.01]$. We did not find associations between choline, betaine or methionine and cognitive outcomes at this age. Results of this study suggest that higher intake of folate in early pregnancy is associated with higher scores on the PPVT-III, a test of receptive language that predicts overall intelligence, at age 3 years.

Keywords: maternal prenatal diet, folate, vitamin B12, choline, methionine, childhood, cognition.

\section{Introduction}

The development and normal functioning of the central nervous system depends on methylation reactions in several processes including myelination, production of monoamine neurotransmitters, dendritic arborisation and synaptic plasticity. ${ }^{1,2}$ These reactions involve the donation of methyl groups by S-adenosylmethionine (SAM) to various substrates. The production of SAM, which is generated from methionine, partly depends on the availability of methyl-donor nutrients from the diet. These nutrients include folate and vitamin B12, which participate in the generation of methionine via the methioninesynthase pathway, and choline and betaine, which are substrates in the betaine : homocysteine methyltransferase pathway.

Epidemiological investigations suggest that inadequate intake of methyl-donor nutrients may be associated with impaired neurocognitive performance in children. ${ }^{3,4}$ Longitudinal studies in adolescents have found inverse associations between vitamin B12 status and measures of neurocognitive performance, ${ }^{5,6}$ and vitamin supplements containing folate and vitamin 
B12 might have a beneficial effect on cognition among people with low intake of these nutrients. ${ }^{7}$

The role of methyl-donor nutrients on neurocognitive function may be particularly relevant at early stages of development, yet relatively few studies have examined the associations between maternal status of these nutrients and cognitive performance in the offspring. Low dietary intake of folate in early pregnancy was related to behavioural problems among 4214 infants in the Netherlands ${ }^{8}$ and in 100 school-age children from the UK, ${ }^{9}$ but possible effects on measures of cognition were not examined. In addition, studies from Spain $^{10}$ and Mexico ${ }^{11}$ indicated that maternal folate status could be related to improved mental development of the infants. One potential limitation of these studies is lack of control for potential confounding by nutritional or other factors that are important for neurobehavioural development. In addition, while these studies focused on folate, the potential effects of other methyl-donors such as maternal choline, betaine and methionine intake on the offspring's cognitive performance have not been researched in humans.

We examined the associations of maternal dietary intake of methyl-donor nutrients including folate, vitamin B12, choline, betaine and methionine during the first and second trimesters of pregnancy with tests of cognitive performance in the offspring at age 3 years among participants of Project Viva, a prospective prebirth cohort study.

\section{Methods}

\section{Study population}

We conducted analyses among participants of Project Viva, an observational longitudinal study designed to examine pregnancy and child health outcomes in relation to multiple prenatal exposures. Detailed descriptions of the cohort have been published elsewhere. ${ }^{12}$ In brief, we invited pregnant women who were receiving care at eight offices from a large group practice in eastern Massachusetts (Harvard Vanguard Medical Associates) to enrol at their first prenatal visit. Exclusion criteria were multiple pregnancy, inability to answer questions in English, planning to move out of the study area before delivery, and gestational age $>22$ completed weeks. At the time of recruitment, we collected data on sociodemographic and anthropometric characteristics and on health status through a brief interview and a take-home self-administered questionnaire. This information included maternal race/ethnicity, age, smoking during pregnancy, pre-pregnancy weight, height, and education, and parity, father's education, child's sex and primary language, and household income. In addition, the interview included detailed questions regarding intake of nutritional supplements (frequency, timing, brand/type and dosage) from 3 months before the participant learned she was pregnant until the interview. The self-administered questionnaire included a 166-item semi-quantitative food frequency questionnaire (FFQ) slightly modified for use in pregnancy from a commonly used adult FFQ, ${ }^{13}$ to assess the woman's diet since her last menstrual period (first trimester FFQ). During a second study visit at 26-28 weeks' gestation, participants completed another FFQ to assess dietary intake during the previous 3 months (second trimester FFQ). The second trimester FFQ was the same as the first trimester except for a briefer assessment of nutritional supplements, which was included in the FFQ. Further details of the FFQ have been published. ${ }^{14}$

We obtained information on neurocognitive outcomes of the children at a follow-up visit that was scheduled at 3 years postpartum. Among 2128 women with livebirths, 1579 were eligible for the 3-year follow-up by virtue of having completed at least one of the FFQs during pregnancy, and having consented for the children's follow-up. At age 3 years, 1292 children $(82 \%)$ underwent in-person examinations. During that visit, research assistants administered the Peabody Picture Vocabulary Test III (PPVT-III) and the Wide Range Assessment of Visual Motor Abilities (WRAVMA) following standardised protocols. They also administered the adult version of PPVT-III to the mothers. The PPVT-III is a test of receptive language that correlates strongly with tests of intelligence. ${ }^{15}$ The WRAVMA $^{16}$ assesses visual-motor, visual-spatial and fine motor abilities through line drawing, picturematching and pegboard subtests. These tests were completed by 1210 children.

Of the 1210 children with neurocognitive assessments at age 3 years and data on maternal diet, 1148 had first trimester and 1083 had second trimester maternal intake data. Compared with the 369 children who were eligible but did not complete the cognitive evaluations, the 1210 participants in this analysis were more likely to have mothers of White race $(74 \%$ vs. $53 \%$ ), and mothers with college or graduate education (72\% vs. $54 \%$ ). 


\section{Data analysis}

\section{Definition of exposures}

Primary exposures of interest were average daily intake of folate, vitamin B12, betaine, choline and methionine during the first and second trimesters of pregnancy, as estimated from the FFQs. We estimated total intake of these nutrients (from foods and supplements) by multiplying the frequency of intake of standard portion sizes of each food item or supplement times its nutrient content, according to the Harvard nutrient composition database used for several large cohort studies. ${ }^{17,18}$ Next, we adjusted intake of each nutrient by total energy intake, using the nutrient residuals method. ${ }^{19}$ We separately considered intake of each nutrient during the first and second trimesters. In addition, we considered peri-conceptional intake of folate and vitamin B12 from supplements only, by using the information collected in the detailed baseline interview that inquired about supplement use between the date of the last menstrual period and 4 weeks' gestation.

\section{Definition of outcomes}

Primary outcomes were PPVT-III and total WRAVMA scores at age 3 years. Secondary endpoints were scores for the line drawing, picture-matching and pegboard subtests of WRAVMA. We treated all neurocognitive outcomes as continuous variables. Each has a standardised population mean of 100 and SD of 15 .

\section{Analyses}

We estimated unadjusted mean changes in cognitive scores per unit of daily intake of each nutrient with the use of linear regression models. For folate, vitamin B12 and choline, we used the recommended dietary allowances (RDA) during pregnancy ${ }^{20}$ as the daily intake unit to estimate the corresponding change in the outcomes; in contrast, for betaine and methionine, we used the value of one standard deviation of the distribution in the study sample because RDA have not been set. Next, we estimated adjusted mean changes and $95 \%$ confidence intervals [CI] with the use of multivariable linear regression models in which each score was the outcome and predictors included all five methyl-donor nutrients of interest in the model at the same time plus potential confounders including maternal race/ethnicity, age, parity, smoking during pregnancy, pre-pregnancy body mass index, maternal PPVT-III score, education, total energy, fish, and iron intake, paternal education, household income, child's sex, and primary language. Models were run separately for each trimester of pregnancy. In addition, we ran models for peri-conceptional intake of folate and vitamin B12 from supplements. We also explored interactions between early folate and vitamin B12 intake on the cognitive endpoints by including in the models a cross-product term between the nutrients. Because the use of nutrient intake values as continuous predictors assumes that the associations with the outcomes follow a linear shape, we conducted supplemental analyses in which nutrients were divided into quartiles of the population distribution. As the results were consistent with a linear relationship, we present results only with continuous measures of nutrient exposures. All analyses were carried out with the use of Statistical Analysis System software (version 9.2; SAS Institute, Inc. Carey, NC).

\section{Results}

Characteristics of women with data on dietary intake during the first or second trimester are presented in Table 1. Correlations between intake of the methyldonor nutrients during the first and second trimesters were $0.32,0.19,0.55,0.51,0.53$ for folate, vitamin B12, choline, betaine and methionine, respectively. Only folate intake increased substantially from the first to second trimesters. Correlations between the methyldonor nutrients were relatively low, except for choline and methionine. During the first trimester, the largest Pearson correlation coefficients were as follows: choline and methionine $=0.75$; folate and betaine $=0.27$; folate and vitamin $\mathrm{B} 12=0.14$. All others were $<0.10$. During the second trimester, Pearson correlations were: choline and methionine $=0.70$; choline and vitamin $\mathrm{B} 12=0.26$; folate and betaine $=0.21$; folate and vitamin $\mathrm{B} 12=0.18$. Others were $<0.17$. Mean (SD) PPVT-III and total standardised WRAVMA scores at age 3 years were 103.9 (14.3) and 102.3 (11.2), and mean scores for the WRAVMA drawing, matching and pegboard subtests were 99.4 (11.2), 108.0 (13.6) and 98.4 (10.7), respectively.

In unadjusted analyses, intake of folate and betaine during the first or second trimester was directly related to PPVT-III scores (Table 2). After adjustment for potential socio-economic, educational and dietary confounders, however, the associations with both nutrients were attenuated and only the relationship between 
Table 1. Characteristics of participants with either first or second trimester dietary intake assessments $(n=1210)$

\begin{tabular}{|c|c|c|}
\hline Characteristics & $n$ & $\%$ or mean $\pm \mathrm{SD}$ \\
\hline \multicolumn{3}{|l|}{ Mother and family } \\
\hline Maternal age at enrolment (years) & 1210 & $32.5 \pm 5.0$ \\
\hline \multicolumn{3}{|l|}{ Race/ethnicity } \\
\hline White & 892 & $73.8 \%$ \\
\hline Black or African American & 139 & $11.5 \%$ \\
\hline Hispanic or Latina & 67 & $5.5 \%$ \\
\hline Other & 111 & $9.2 \%$ \\
\hline \multicolumn{3}{|l|}{ Parity } \\
\hline 0 & 577 & $47.7 \%$ \\
\hline 1 & 434 & $35.9 \%$ \\
\hline 2 & 153 & $12.6 \%$ \\
\hline$\geq 3$ & 46 & $3.8 \%$ \\
\hline Pre-pregnancy body mass index $\left(\mathrm{kg} / \mathrm{m}^{2}\right)$ & 1206 & $24.6 \pm 5.1$ \\
\hline \multicolumn{3}{|l|}{ Smoking during index pregnancy } \\
\hline No & 1062 & $89.7 \%$ \\
\hline Yes & 122 & $10.3 \%$ \\
\hline Mother's PPVT-III score & 1181 & $106.1 \pm 14.5$ \\
\hline \multicolumn{3}{|l|}{ Highest grade level completed by mother } \\
\hline Some college or less & 340 & $28.1 \%$ \\
\hline College graduate or more & 869 & $71.9 \%$ \\
\hline \multicolumn{3}{|l|}{ Highest grade level completed by father } \\
\hline Some college or less & 345 & $30.7 \%$ \\
\hline College graduate or more & 778 & $69.3 \%$ \\
\hline \multicolumn{3}{|l|}{ Maternal dietary intake $\mathrm{a}^{\mathrm{a}}$} \\
\hline Folate, peri-conceptional supplements ${ }^{\mathrm{b}}(\mu \mathrm{g} /$ day) & 1148 & $405 \pm 405$ \\
\hline Vitamin B12, peri-conceptional supplements ( $\mu \mathrm{g} /$ day) & 1148 & $4.5 \pm 14.0$ \\
\hline \multicolumn{3}{|l|}{ First trimester } \\
\hline Total energy intake (kcal/day) & 1148 & $2090 \pm 655$ \\
\hline Folate, total ( $\mu \mathrm{g} /$ day $)$ & 1148 & $949 \pm 390$ \\
\hline Folate, food sources ( $\mu \mathrm{g} /$ day) & 1148 & $367 \pm 126$ \\
\hline Vitamin B12, total ( $\mu \mathrm{g} /$ day) & 1148 & $10.8 \pm 15.7$ \\
\hline Vitamin B12, food sources ( $\mu \mathrm{g} /$ day) & 1148 & $6.3 \pm 4.0$ \\
\hline Choline (mg/day) & 1148 & $332 \pm 63$ \\
\hline Betaine (mg/day) & 1148 & $243 \pm 108$ \\
\hline Methionine (mg/day) & 1148 & $2053 \pm 408$ \\
\hline Iron (mg/day) & 1148 & $34.2 \pm 17.6$ \\
\hline Fish (servings/week) & 1148 & $1.7 \pm 1.4$ \\
\hline \multicolumn{3}{|l|}{ Second trimester } \\
\hline Total energy intake (kcal/day) & 1083 & $2139 \pm 607$ \\
\hline Folate, total ( $\mu \mathrm{g} /$ day) & 1083 & $1272 \pm 381$ \\
\hline Folate, food sources ( $\mu \mathrm{g} /$ day) & 1083 & $367 \pm 128$ \\
\hline Vitamin B12, total ( $\mu \mathrm{g} /$ day) & 1083 & $10.6 \pm 6.4$ \\
\hline Vitamin B12, food sources ( $\mu \mathrm{g} /$ day $)$ & 1083 & $6.3 \pm 3.6$ \\
\hline Choline (mg/day) & 1083 & $325 \pm 64$ \\
\hline Betaine (mg/day) & 1083 & $234 \pm 103$ \\
\hline Methionine (mg/day) & 1083 & $2065 \pm 375$ \\
\hline Iron (mg/day) & 1083 & $49.4 \pm 24.2$ \\
\hline Fish (servings/week) & 1083 & $1.6 \pm 1.4$ \\
\hline \multicolumn{3}{|l|}{ Child } \\
\hline Sex, \% female $(n)$ & 608 & $50.3 \%$ \\
\hline Age at 3 years testing (months) & 1210 & $39.5 \pm 4.1$ \\
\hline Speaks English as a second language & 41 & $3.4 \%$ \\
\hline \multicolumn{3}{|l|}{ Cognitive test scores at age 3 years } \\
\hline PPVT-III & 1186 & $103.9 \pm 14.3$ \\
\hline \multicolumn{3}{|l|}{ WRAVMA } \\
\hline Total standard & 1147 & $102.3 \pm 11.2$ \\
\hline Drawing & 1195 & $99.4 \pm 11.2$ \\
\hline Matching & 1167 & $108.0 \pm 13.6$ \\
\hline Pegboard & 1192 & $98.4 \pm 10.7$ \\
\hline
\end{tabular}

${ }^{a}$ Nutrient values are adjusted for total energy intake (residuals method).

${ }^{\mathrm{b}}$ Intake from supplements at $0-4$ weeks of gestation.

PPVT, Peabody Picture Vocabulary Test. WRAVMA, Wide Range Assessment of Visual Motor Abilities. 
Table 2. Differences in cognitive test scores at age 3 according to maternal intake of methyl-donor nutrients during pregnancy ${ }^{\mathrm{a}}$

\begin{tabular}{|c|c|c|c|c|}
\hline & \multicolumn{2}{|c|}{ PPVT-III } & \multicolumn{2}{|c|}{ Total WRAVMA } \\
\hline & $\begin{array}{l}\text { Unadjusted difference } \\
\qquad[95 \% \mathrm{CI}]\end{array}$ & $\begin{array}{c}\text { Adjusted difference }^{\mathrm{b}} \\
{[95 \% \mathrm{CI}]}\end{array}$ & $\begin{array}{l}\text { Unadjusted difference } \\
\qquad[95 \% \mathrm{CI}]\end{array}$ & $\begin{array}{c}\text { Adjusted difference } \\
{[95 \% \mathrm{CI}]}\end{array}$ \\
\hline \multicolumn{5}{|l|}{ Folate, per $600 \mu \mathrm{g} /$ day } \\
\hline Early pregnancy supplements & $4.4[3.2,5.6]$ & $1.2[-0.1,2.4]$ & $1.3[0.4,2.3]$ & $0.1[-1.0,1.1]$ \\
\hline First trimester & $5.3[4.0,6.5]$ & $1.6[0.1,3.1]$ & $1.9[0.9,2.9]$ & $0.3[-1.0,1.6]$ \\
\hline Second trimester & $3.0[1.6,4.4]$ & $0.9[-0.5,2.2]$ & $0.4[-0.6,1.5]$ & $-0.7[-1.9,0.6]$ \\
\hline \multicolumn{5}{|l|}{ Vitamin B12, per $2.6 \mu \mathrm{g} /$ day } \\
\hline Early pregnancy supplements & $0.2[0.1,0.4]$ & $0.1[-0.1,0.2]$ & $0.1[-0.1,0.2]$ & $0.0[-0.1,0.2]$ \\
\hline First trimester & $0.1[-0.1,0.2]$ & $0.0[-0.1,0.1]$ & $0.1[-0.1,0.2]$ & $0.0[-0.1,0.2]$ \\
\hline Second trimester & $-0.4[-0.8,-0.1]$ & $-0.4[-0.8,-0.1]$ & $-0.1[-0.3,0.2]$ & $0.0[-0.3,0.2]$ \\
\hline \multicolumn{5}{|l|}{ Choline, per $450 \mathrm{mg} /$ day } \\
\hline First trimester & $-1.7[-7.6,4.2]$ & $-3.1[-11.0,4.8]$ & $0.1[-4.6,4.9]$ & $-2.8[-9.9,4.3]$ \\
\hline Second trimester & $-0.4[-6.5,5.7]$ & $0.8[-7.4,9.0]$ & $0.3[-4.6,5.2]$ & $-0.4[-7.6,6.8]$ \\
\hline \multicolumn{5}{|l|}{ Betaine, per $100 \mathrm{mg} /$ day } \\
\hline First trimester & $2.2[1.4,2.9]$ & $0.4[-0.4,1.1]$ & $0.6[0.0,1.2]$ & $0.0[-0.6,0.7]$ \\
\hline Second trimester & $2.2[1.4,3.0]$ & $0.4[-0.3,1.2]$ & $0.9[0.2,1.5]$ & $0.1[-0.6,0.8]$ \\
\hline \multicolumn{5}{|l|}{ Methionine, per $400 \mathrm{mg} /$ day } \\
\hline First trimester & $0.2[-0.6,1.0]$ & $0.4[-0.7,1.5]$ & $0.4[-0.2,1.0]$ & $0.5[-0.5,1.5]$ \\
\hline Second trimester & $0.2[-0.7,1.1]$ & $-0.3[-1.5,0.9]$ & $0.4[-0.4,1.1]$ & $0.0[-1.1,1.1]$ \\
\hline
\end{tabular}

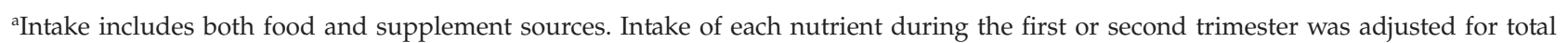
energy using the method of the residuals. Sample sizes for the first and second trimesters are 1148 and 1083, respectively.

${ }^{b}$ From trimester-specific linear regression models with cognitive test scores as the outcome and covariates that included all five nutrients in the table at the same time plus maternal race/ethnicity, age, parity, smoking during pregnancy, pre-pregnancy body mass index, PPVT, education, total energy, fish, and iron intake, paternal education, household income, child's sex, and English as primary language. Models for the peri-conceptional period did not include choline, betaine or methionine.

PPVT, Peabody Picture Vocabulary Test. WRAVMA, Wide Range Assessment of Visual Motor Abilities.

folate intake during the first trimester and PPVT-III scores remained statistically significant (Table 2). Every increment of $600 \mu \mathrm{g} /$ day of folate intake from foods and supplements during the first trimester was associated with a 1.6 point [ $95 \%$ CI $0.1,3.1 ; P=0.04$ ] higher PPVT-III score at age 3 years. The estimate for $600 \mu \mathrm{g} /$ day folate from peri-conceptional supplements only was 1.2 points [ $95 \% \mathrm{CI}-0.1,2.4 ; P=0.07]$; from supplements only during the first trimester, 1.7 points [95\% CI 0.2, 3.3; $P=0.03]$; and from foods only during the first trimester, -0.2 points $[95 \%$ CI $-4.1,3.7$; $P=0.92]$. There was a weak, inverse association between vitamin B12 intake during the second trimester and PPVT-III score; every $2.6 \mu \mathrm{g} /$ day increment was related to a 0.4 points [ $95 \% \mathrm{CI}-0.8,-0.1 ; P=0.01$ ] lower PPVT-III. There were no interactions between intakes of folate and vitamin B12. Intake of methyldonor nutrients during pregnancy was not associated with total WRAVMA standard scores (Table 2), or with the drawing, matching or pegboard subtests (data not shown). Additional adjustment for maternal alcohol intake at each of the exposure periods considered yielded essentially identical results.

\section{Discussion}

In this longitudinal study, maternal folate intake during early pregnancy was positively related to PPVTIII scores at age 3 years, independent of nutritional and sociobehavioural potential confounders. On the other hand, there was a weak, inverse association between intake of vitamin B12 during the second trimester and the child's performance on the PPVT-III. We did not find associations between maternal intake of choline, methionine or betaine and tests of cognitive performance in the offspring.

Some previous studies have suggested that higher intake of folate during early pregnancy could be associated with improved cognitive or behavioural performance in the offspring. For example, among Spanish women, intake of folic acid from supplements during the first trimester of pregnancy was associated with 
higher verbal and motor performance scores and lower risk of inattention symptoms in the offspring at 4 years of age, independent of sociodemographic characteristics and iron supplementation. ${ }^{10}$ In the 'Generation $\mathrm{R}^{\prime}$ study of Rotterdam mothers and their children, intake of folate from supplements during the first 10 weeks of pregnancy was related to decreased risk of behavioural problem syndromes (emotionally reactive, anxious/depressed, somatic complaints, withdrawn, attention problems and aggressive behaviour) in the children at age 18 months, after adjusting for maternal age, country of origin, education and psychopathology. ${ }^{8}$ Total dietary folate intake and erythrocyte folate concentrations during the first trimester of pregnancy were inversely related to scores of hyperactivity and peer problems in the offspring at 8 years of age in a cohort of Southampton, UK, ${ }^{9}$ independent of maternal smoking and alcohol or iron intake. Among Mexican mothers with a polymorphism of the methylenetetrahydrofolate reductase enzyme, low total dietary intake of folate during the first trimester of pregnancy was related to lower mental development scores during the infant's first year of age. ${ }^{11}$ Despite differences in the domains and test batteries of cognitive and behavioural function that have been examined across studies, our finding of a positive association between folate intake from foods and supplements during the first trimester and PPVT-III scores at 3 years is consistent with those reported from other settings. Because our analyses were adjusted for many important confounders, especially the mother's own PPVT-III score and sociodemographic characteristics including parity, the estimate of association between folate intake and PPVT-III is likely to be less biased than those reported before.

The association of folate intake and PPVT-III was observed for total folate intake and for folic acid from supplements but not for folate from foods alone. Mean folate intake from foods during the first trimester, $367 \mu \mathrm{g} /$ day, was lower than the recommended $600 \mu \mathrm{g} /$ day. When folic acid from supplements was considered, total folate intake increased to more than twice the mean value from foods alone. This suggests that a potential effect of folate on cognitive function may be observed only at high intake. This high level of intake might only be achievable through folic acid supplementation. Not only was intake from foods lower than that from supplements in this population, but the bioavailability of folate from foods is only about half that of the folic acid present in supplements. ${ }^{21,22}$ Folic acid bioavailability from supplements may have been underestimated in comparison with that of folate from foods in this study, as the calculation of folate intake from supplements was not adjusted for differences in bioavailability between food and supplement sources.

We did not find associations between folate intake during the second trimester of pregnancy and cognitive outcomes. Previous observational studies of cognition in relation to maternal folate status in the second trimester reported protective effects; ${ }^{23,24}$ nevertheless, folate status indicators used in these studies could be surrogates of folate at earlier stages. Folate status after the first trimester was not associated with measurements of neurocognitive development in a study of low-income children from the $\mathrm{US}^{25}$ and current evidence from intervention trials does not support an effect of folate alone administered after the first trimester of pregnancy on neurocognitive function. ${ }^{26,27} \mathrm{~A}$ potential effect of folate on cognition could be specific to early pregnancy. The biological mechanisms underlying this effect are speculative; they could be related to folate-mediated alterations in DNA methylation that may result in differential expression of proteins related to production of neurotransmitters, synaptic formation or myelination in the central nervous system.

We found a weak, albeit statistically significant, inverse relationship between vitamin B12 intake during the second trimester and PPVT-III scores at age 3 years. In a previous study in India, 9-year-old children whose mothers had high vitamin B12 serostatus at gestation week 28 scored 6\% lower on the Raven's Coloured Progressive Matrices test, a proxy for intelligence, than did children born to mothers with low vitamin B12. ${ }^{28}$ That difference, however, was not statistically significant; on the other hand, there were direct associations between maternal vitamin B12 and other cognitive outcomes including sustained attention (13\% difference) and short-term memory (12\% difference). In a cross-sectional study of Indian school-age children, serum levels of vitamin B12 were inversely related to short-term memory and a mental processing index. ${ }^{29}$ The nature of the inverse relationship between vitamin B12 status and child cognition reported in some studies is unclear at this point and warrants further examination in additional studies.

In our study, maternal intake of other nutrients involved in methyl donation pathways, including choline, betaine and methionine, was not related to cognitive outcomes of the offspring. In a different cohort, maternal serum choline concentrations during 
the second or third trimester were also unrelated to intelligence in the children at 5 years of age. ${ }^{30}$ Results from these studies are in contrast with evidence from animal research, which consistently indicates that choline is an essential nutrient for adequate neurodevelopment. ${ }^{31}$ Women in our study were not receiving supplements of these nutrients; their mean intake of choline in the first $(332 \mathrm{mg} /$ day $)$ and second ( $325 \mathrm{mg}$ /day) trimesters was below the $450 \mathrm{mg} /$ day currently recommended during pregnancy and variability seemed relatively low. Whether doses above usual dietary intakes could have an impact on neurocognitive outcomes deserves additional investigation. It is also possible that the cognitive effects of these nutrients become evident at later ages.

Our study has several strengths. The prospective nature of the design precludes reverse causation. While misclassification of nutrient intakes is possible, random error in the assessment of the exposure would be likely to lead to an attenuation of the underlying effect. We were able to control for major potential confounders in the analysis, including measures of maternal intelligence, socio-economic status and dietary intake of other nutrients that are relevant for neurodevelopment.

The study also has some limitations. The reference amount of folate intake we used to estimate the effect on cognition, $600 \mu \mathrm{g} /$ day, is relatively high and likely to be achievable only through supplement use. The effect associated with this amount might be considered modest, about 1.5 points in the PPVT-III score scale; nevertheless, the underlying effect could be higher in the absence of measurement error. Iron intake is a potential confounder of the association between folate and cognition because it may be found in the same multimicronutrient supplements as folate and has well-known effects on cognitive development. Although we adjusted for iron intake, some residual confounding by iron cannot be completely ruled out. Generalisability of results may be limited as cohort participants in whom neurodevelopmental testing was performed differed from those who were excluded with regard to race and education level. Finally, because several comparisons were made, chance cannot be fully discarded as a potential explanation of the findings.

In conclusion, folate intake during early pregnancy, particularly from supplements, among participants of Project Viva was associated with increased PPVT-III in their children at age 3 years. Intakes of other methyl- donor nutrients at levels provided by the usual diet were not related to neurocognitive performance, except for a weak inverse relationship of vitamin B12 intake with PPVT-III during the second trimester. Because folate is a substrate for methylation reactions, future studies should examine whether DNA methylation, a mechanism of epigenetic regulation, is associated with neurocognitive development indicators in the offspring. The potential effects of supplemental doses of other methyl-donor nutrients deserve future investigation. Whether increasing peri-conceptional folate intake over current recommendations improves neurocognitive performance of the offspring is an open research question that requires testing in intervention studies.

\section{Acknowledgements}

This study was supported by the National Institutes of Health (grant numbers HD34568, HL69425, HL77504 and HL68041).

Eduardo Villamor conceived the study question and wrote the first draft of the manuscript. Sheryl L. Rifas-Shiman conducted the data analyses. Matthew W. Gillman and Emily Oken contributed to the interpretation of results and are principal investigators of Project Viva. All authors contributed to the manuscript write-up. Villamor, Rifas-Shiman, Gillman, Oken have no conflict of interest in relation to the manuscript.

\section{References}

1 Selhub J, Bagley LC, Miller J, Rosenberg IH. B vitamins, homocysteine, and neurocognitive function in the elderly. American Journal of Clinical Nutrition 2000; 71:614S-620S.

2 Levenson JM, Roth TL, Lubin FD, Miller CA, Huang IC, Desai $\mathrm{P}$, et al. Evidence that DNA (cytosine-5) methyltransferase regulates synaptic plasticity in the hippocampus. Journal of Biological Chemistry 2006; 281:15763-15773.

3 Black MM. Effects of vitamin B12 and folate deficiency on brain development in children. Food and Nutrition Bulletin 2008; 29:S126-S131.

4 Dror DK, Allen LH. Effect of vitamin B12 deficiency on neurodevelopment in infants: current knowledge and possible mechanisms. Nutrition Reviews 2008; 66:250-255.

5 Louwman MW, van Dusseldorp M, van de Vijver FJ, Thomas CM, Schneede J, Ueland PM, et al. Signs of impaired cognitive function in adolescents with marginal cobalamin status. American Journal of Clinical Nutrition 2000; 72:762-769.

6 Gewa CA, Weiss RE, Bwibo NO, Whaley S, Sigman M, Murphy SP, et al. Dietary micronutrients are associated with higher cognitive function gains among primary school 
children in rural Kenya. British Journal of Nutrition 2009; 101:1378-1387.

7 Kang JH, Cook N, Manson J, Buring JE, Albert CM, Grodstein F. A trial of B vitamins and cognitive function among women at high risk of cardiovascular disease. American Journal of Clinical Nutrition 2008; 88:1602-1610.

8 Roza SJ, van Batenburg-Eddes T, Steegers EA, Jaddoe VW, Mackenbach JP, Hofman A, et al. Maternal folic acid supplement use in early pregnancy and child behavioural problems: The Generation R Study. British Journal of Nutrition 2010; 103:445-452.

9 Schlotz W, Jones A, Phillips DI, Gale CR, Robinson SM, Godfrey KM. Lower maternal folate status in early pregnancy is associated with childhood hyperactivity and peer problems in offspring. Journal of Child Psychology and Psychiatry 2010; 51:594-602.

10 Julvez J, Fortuny J, Mendez M, Torrent M, Ribas-Fito N, Sunyer J. Maternal use of folic acid supplements during pregnancy and four-year-old neurodevelopment in a population-based birth cohort. Paediatric and Perinatal Epidemiology 2009; 23:199-206.

11 del Rio Garcia C, Torres-Sanchez L, Chen J, Schnaas L, Hernandez C, Osorio E, et al. Maternal MTHFR 677C >T genotype and dietary intake of folate and vitamin $\mathrm{B}(12)$ : their impact on child neurodevelopment. Nutritional Neuroscience 2009; 12:13-20.

12 Gillman MW, Rich-Edwards JW, Rifas-Shiman SL, Lieberman ES, Kleinman KP, Lipshultz SE. Maternal age and other predictors of newborn blood pressure. Journal of Pediatrics 2004; 144:240-245.

13 Willett WC, Sampson L, Stampfer MJ, Rosner B, Bain C, Witschi J, et al. Reproducibility and validity of a semiquantitative food frequency questionnaire. American Journal of Epidemiology 1985; 122:51-65.

14 Fawzi WW, Rifas-Shiman SL, Rich-Edwards JW, Willett WC, Gillman MW. Calibration of a semi-quantitative food frequency questionnaire in early pregnancy. Annals of Epidemiology 2004; 14:754-762.

15 Williams KT, Wang JJ. Technical References to the Peabody Picture Vocabulary Test, 3rd edn. (PPVT-III). Circle Pines, MN: American Guidance Service, Inc., 1997.

16 Adams W, Sheslow D. WRAVMA (Wide Range Assessment of Visual Motor Abilities). Wilmington, DE: Wide Range, Inc., 1995.

$17 \mathrm{Hu}$ FB, Stampfer MJ, Manson JE, Rimm E, Colditz GA, Rosner BA, et al. Dietary fat intake and the risk of coronary heart disease in women. New England Journal of Medicine 1997; 337:1491-1499.

18 Rimm EB, Giovannucci EL, Stampfer MJ, Colditz GA, Litin LB, Willett WC. Reproducibility and validity of an expanded self-administered semiquantitative food frequency questionnaire among male health professionals. American Journal of Epidemiology 1992; 135:1114-1126.
19 Willett WC, Howe GR, Kushi LH. Adjustment for total energy intake in epidemiologic studies. American Journal of Clinical Nutrition 1997; 65:1220S-1228S.

20 National Academy of Sciences, Institute of Medicine, Board. FaN. Dietary Reference Intakes for Thiamin, Riboflavin, Niacin, Vitamin B6, Folate, Vitamin B12, Pantothenic Acid, Biotin, and Choline. Washington, D.C.: National Academic Press, 1998.

21 Sauberlich HE, Kretsch MJ, Skala JH, Johnson HL, Taylor PC. Folate requirement and metabolism in nonpregnant women. American Journal of Clinical Nutrition 1987; 46:1016-1028.

22 Cuskelly GJ, McNulty H, Scott JM. Effect of increasing dietary folate on red-cell folate: implications for prevention of neural tube defects. Lancet 1996; 347:657-659.

23 Gross RL, Newberne PM, Reid JVO. Adverse effects of infant development associated with maternal folic acid deficiency. Nutrition Reports International 1974; 10:241-248.

24 Veena SR, Krishnaveni GV, Srinivasan K, Wills AK, Muthayya S, Kurpad AV, et al. Higher maternal plasma folate but not vitamin B-12 concentrations during pregnancy are associated with better cognitive function scores in 9- to 10-year-old children in South India. Journal of Nutrition 2010; 140:1014-1022.

25 Tamura T, Goldenberg RL, Chapman VR, Johnston KE, Ramey SL, Nelson KG. Folate status of mothers during pregnancy and mental and psychomotor development of their children at five years of age. Pediatrics 2005; 116:703-708.

26 Li Q, Yan H, Zeng L, Cheng Y, Liang W, Dang S, et al. Effects of maternal multimicronutrient supplementation on the mental development of infants in rural western China: follow-up evaluation of a double-blind, randomized, controlled trial. Pediatrics 2009; 123:e685-e692.

27 Campoy C, Escolano-Margarit MV, Ramos R, Parrilla-Roure M, Csabi G, Beyer J, et al. Effects of prenatal fish-oil and 5-methyltetrahydrofolate supplementation on cognitive development of children at $6.5 \mathrm{y}$ of age. American Journal of Clinical Nutrition 2011; 94:1880S-1888S.

28 Bhate V, Deshpande S, Bhat D, Joshi N, Ladkat R, Watve S, et al. Vitamin B12 status of pregnant Indian women and cognitive function in their 9-year-old children. Food and Nutrition Bulletin 2008; 29:249-254.

29 Eilander A, Muthayya S, van der Knaap H, Srinivasan K, Thomas T, Kok FJ, et al. Undernutrition, fatty acid and micronutrient status in relation to cognitive performance in Indian school children: a cross-sectional study. British Journal of Nutrition 2010; 103:1056-1064.

30 Signore C, Ueland PM, Troendle J, Mills JL. Choline concentrations in human maternal and cord blood and intelligence at $5 \mathrm{y}$ of age. American Journal of Clinical Nutrition 2008; 87:896-902.

31 Zeisel SH, Niculescu MD. Perinatal choline influences brain structure and function. Nutrition Reviews 2006; 64:197-203. 